\title{
Giardia lambliaaffecting humans in Sohag governorate and its relation with some physical measurements
}

\author{
Hanaa A. El-Hady*, Amal M. Ahmed*, Noha S. Ahmed*, Hesham I. Osman* \\ *Medical Parasitology department, Faculty of Medicine, Sohag University, Egypt. \\ Correspondence to Hesham I. Osman, Department of Medical Parasitology, Faculty of \\ Medicine, Sohag University, Egypt
}

\begin{abstract}
Background and study aim: Giardiasis is a gastrointestinal disease, caused by the protozoan parasites Giardia lamblia. Thisinfection occurs through ingestion of contaminated water or food by Giardialamblia cysts. The aim of this study was to correlate between the presence of Giardia lambilia and some physical measurements.

Subjects and methods: experimental study was performed at the laboratories of Parasitology Department, Faculty of Medicine, Sohag University from October 2016 to October 2017. It was done on 93 patients, who had Giardia from different localities in Sohag governorate after examination of stool sambles by saline and iodine wet mount. History taking and some physical measurements, as weight and height, using a meter, a scale and growth charts were taken for cases included in this study.

Results: There was a decrease in height, 50 (53.8\%), weight for height, 49 (52.7\%), body mass index, 45 (48.4\%), and weight, 33 (35.5\%), of cases with Giardia lambliainfection by different proportions.
\end{abstract}

Keywords: Giardiasis, Giardia lamblia, gastrointestinal disease, physical measurements.

\section{Introduction}

G. lamblia is one of the most common intestinal protozoa present in humans, both in Egypt and worldwide[1]. The rate of human infection with G. lambliain Egypt varies between $10 \%$ - 34.6\% [2].Children, and immunocompromised individuals are the most affected by Giardia In children. There are many effects by Giardia lamblia on growth, nutrition and cognitive functions have been reported[3]. The World Health Organization (WHO) recognized giardiasis as a neglected disease associated with poverty and impaired development [4]. Transmission of infection occurs by ingestion of viable cysts with contaminated food or drink [5]. Clinical presentations of giardiasis vary, ranging from asymptomatic infection to chronic symptomatic infection. Infected patients present with diarrhea, steatorrhea, flatulence, and malabsorption[6].

Subjects and methods:
This expermental study was conducted from October 2016 to October 2017at the

laboratories of Parasitology Department, Faculty of Medicine, Sohag University.

- Stool sample collection and examination and preservation:

Stool samples had been collected from 525 patients who had diarrhea from different cities in Sohag Governorate, 93 stool samples only had Giardia after examination by saline and iodine wet mount using the light microscopic. Every positive sample for Giardia lamblia had been divided into two parts and put in eppendorf tubes. the first one of them was examined immediately, the second put in formalin $10 \%$ in a ratio 1 to 3 . 
- Measurement of some physical measurements, as weight and height using a meter and scale for cases included in the study.

- Growth charts for weight, height, weight for height and body mass index for every case included in the study. These growth charts were according to the world health organization site. (www.who.com).

\section{Statistical analysis:}

Data were organized, tabulated, and statistically analyzed using SPSS version, 23.00. $\mathrm{P}$ values were calculated. Chisquare test $\left(\chi^{2}\right)$ was used to compare the frequency data. $\mathrm{P}$ value $<0.05$ indicates significant $(\mathrm{S})$ values. $\mathrm{P}$ valu $<0.01$ indicates highly significant (HS) values. $\mathrm{P}$ value $>0.05$ Non significant (NS).

\section{Results}

- out of 93 cases there were $60(64.5 \%)$ male and $33(35.5 \%)$ female. The $\mathrm{P}$ value for gender distribution using legacy dialog non parametric test was 0.05 (significant). And the Chi-square $(\chi 2)$ test for gender distribution was 7.83.

- The age of patients ranged from 9 months to 18 years. The cases with Giardia lamblia included in this study was classified to 4 age groups as shown in table (1).

\begin{tabular}{|c|c|c|c|}
\hline Age groub & Giardia lamblia & P value & Chi-square $\left(\chi^{2}\right)$ test \\
\hline Age $<2$ years & $5(5.4 \%)$ & \multirow{4}{*}{0.001 (HS) } & \multirow{4}{*}{$x_{0}$} \\
\hline Age 2-6 years & $67(72.1 \%)$ & & \\
\hline Age 6-12 years & $19(20.3 \%)$ & & \\
\hline Age 12-18 years & 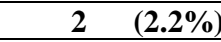 & & \\
\hline
\end{tabular}

Table 1: The relation between age groups and Giardia lamblia:

- The relation between locality and Giardia is shown in table (2)

\begin{tabular}{|l|l|l|l|}
\hline Locality & Giardia lamblia & P value & Chi-square $(\chi 2)$ test \\
\hline Urban & $19(20.4 \%)$ & $0.001(\mathrm{HS})$ & 32.52 \\
\cline { 1 - 2 } Rural & $\mathbf{7 4}(79.6 \%)$ & & \\
\hline
\end{tabular}

Table 2: The relation between locality and Giardia lamblia:

- The relation between weight and Giardia lamblia is shown in table (3).

\begin{tabular}{|l|l|l|l|}
\hline Weight & Giardia lamblia & P value & $\begin{array}{l}\text { Chi-square }(\chi 2) \\
\text { test }\end{array}$ \\
\cline { 1 - 2 } Weight $>$ 50 percentile & $36(38.7 \%)$ & \multirow{2}{*}{$0.28(\mathrm{NS})$} & \multirow{2}{*}{2.516} \\
\cline { 1 - 2 } & $33(35.5 \%)$ & & \\
\cline { 1 - 2 } Weight $<50$ percentile & $2425.8 \%)$ & & \\
\cline { 1 - 3 } & & & \\
\hline
\end{tabular}

Table 3: The relation between weight and Giardia lamblia:

- The relation between height and Giardia lamblia is shown in table (4).

\begin{tabular}{|l|l|l|l|}
\hline Height & Giardia lamblia & P value & Chi-square $(\chi 2)$ test \\
\cline { 1 - 2 } Height $>$ 50 percentile & $31(33.3 \%)$ & \multirow{2}{*}{$0.001($ HS) } & \multirow{2}{*}{23.29} \\
\cline { 1 - 2 } Height $<50$ percentile & $50(53.8 \%)$ & & \\
\cline { 1 - 3 } Height equal to 50 percentile & $12(12.9 \%)$ & & \\
\hline
\end{tabular}

Table 4: The relation between height and Giardia lamblia: 
- The relation between weight for height and Giardia lamblia is shown in table (5).

\begin{tabular}{|c|c|c|c|}
\hline Weight for height & Giardia lamblia & $P$ value & Chi-square $\left(\chi^{2}\right)$ test \\
\hline Weight for height $>50$ percentile & $36(38.7 \%)$ & \multirow{3}{*}{0.001 (HS) } & \multirow{3}{*}{28.323} \\
\hline Weight for height $<50$ percentile & $49(52.7 \%)$ & & \\
\hline $\begin{array}{l}\text { Weight for height equal to } 50 \\
\text { percentile }\end{array}$ & $8(8.6 \%)$ & & \\
\hline
\end{tabular}

\section{Table 5: The relation between weight for height and Giardia lamblia:}

- The relation between body mass index and Giardia lamblia is shown in table (6).

\begin{tabular}{|l|l|l|c|}
\hline Body mass index & Giardia lamblia & P value & Chi-square $(\chi 2)$ test \\
\cline { 1 - 2 } Body mass index $>50$ percentile & $37(39.8 \%)$ & \multirow{2}{*}{$0.001(\mathrm{HS})$} & 20.387 \\
\hline Body mass index< 50 percentile & $\mathbf{4 5 ( 4 8 . 4 \% )}$ & & \\
\cline { 1 - 2 } $\begin{array}{l}\text { Body mass index equal to 50 } \\
\text { percentile }\end{array}$ & $\mathbf{1 1}(11.8 \%)$ & & \\
\hline
\end{tabular}

Table 6: The relation between body mass index and Giardia lamblia:

\section{Discussion}

The intestinal protozoan Giardia lambliawas frequently found in diarrheal disease throughout the world affecting humans and other mammalian species [7]. This study was done on 93 patients, who had Giardia from different localities in Sohag governorate after examination of stool sambles by saline and iodine wet mount. History taking and some physical measurements, as weight and height, using a meter, a scale and growth charts were taken for cases included in this study.

In the current study, 93 positive stool samples for Giardia lambliaby microscopy were detected.

As regards the relation of sex to the prevalence of giardiasis, out of the 93 positive samples there were $60(64.5 \%)$ males while $33(35.5 \%)$ female. The variation in sex distribution was found to be statistically highly significant $(\mathrm{PV}=$ 0.005). This agreed with Julioet al.[8],Mohran.[9] and De Lucioet al.[10], who stated that the incidence of giardiasis is higher in males than in females. These results disagreed with Duldovaet al.[11], who stated that the prevalence in females was higher than males. They assumed that due to caring of these females to their own children or from working in nursing homes or care-day centers.

As regards relation of age to the prevalence of giardiasis in the present study, the highest incidence was between 2 - 6 years represented $72.1 \%$ then $6-12$ years represented $20.3 \%$ then $<2$ years represented $5.4 \%$ lastly 12 - 18 years represented $2.2 \%$. The variation in age distribution was found to be statistically highly significant $(\mathrm{PV}=0.001)$.

This study showed that, the highest group was 2 - 6 years and this can be explained by highly active attitude of these children who play outside home and this makes them more subjected to highly polluted surrounding area by Giardia cyst not only from humans as a source of infection but also from animals as an another source of infection.

These results agreed with Bernard $\boldsymbol{e t}$ al. [12], Who stated that the highest 
prevalence was between 3 to 5 years, and Mohran. [9], who stated that, the highest prevalence was between 1 - 10 years.

These results disagreed with Heehonget al. [13], and El-Badryet al. [14], who stated that giardiasis was highest in children aged 6 to 12 years.

The results of this study showed that there was a decrease in weight, height, weight for height, and body mass index of children with Giardia infection by different proportions.

This was consistent with previous findings in many different studies as in: Niehauset al., (2002) in Brazil, Simseket al., (2004) in Peru Al-Mekhlafiet al.,(2005) in Malaysia, Sadjjadi and Tanideh, (2005) in Iran,Botero-Garceset al., (2009) in Colombia, and Koruketal., (2010) in Turki. All these results found a strong association between Giardia infection and undernutrition, wasting and stunting among children but without determining genotypes of Giardia lamblia. Also there was a previous study among Brazilian children showed that Giardiainfected children had a double risk for stunted growth as compared to other children (Muniz and Queiroz, 2008).

The results in this study disagreed with Lunnet al., (1999) in Gambia and Hollmet al., (2008), that they found that there was no significant association between Giardia lambliainfection and malnutrition.

The difference with these results could be attributed to the low prevalence of $G$. duodenalis reported by these studies as compared to the present study.

The results in this study showed that there was an association with some physical features like underweight, stunting and wasting with Giardia lambliainfection. However, it is very probable that Giardia infection is one of the several factors associated with low nutritional status, together with sanitary and socioeconomic conditions.

\section{Conclusion}

We concluded that However diarrhea was the first complaint that affected all cases, abdominal colic was the second most common complaint affecting $84(90.3 \%)$ cases, followed by failure to thrive affecting $32(34.5 \%)$ cases, followed by abdominal distension affecting $26(28 \%)$ cases, and vomiting affecting $6(6.6 \%)$ of cases.

\section{References}

1. Ismail MA, El-Akkad DM, Rizk EM, ElAskaryHM, El-Badry AA. Molecular seasonality of Giardialamblia in a cohort of Egyptian children: A circannualpattern. Parasitol Res, 2016; 115(11): 4221-4227.

2. Bayoumy, A.M., Mohammed, K.A., Shahat, S.A., Ghannam,M.M. and Gazy, M.S. (2010): "Role of parasites among chronic diarrheic patients." Journal of the Egyptian Society of Parasitology. 40 (3): 679-698.

3. Rogawski, E.T., Bartelt, L.A., PlattsMills, J.A., Seidman, J.C., Samie, A., Havt, A., et al., (2017):Determinants and impact of Giardia infection in the first 2 years of life in the MAL-ED birth cohort. $J$. Pediatr. Infect. Dis. Soc .6(2): 153-160.

4. Savioli, L., Smith, H., and Thompson, A., (2006): Giardia and Cryptosporidium join the 'Neglected diseases initiative. Trends Parasitol. 22(5): 203-208.

5. Budu-Amoako, E., Greenwood, S.J., Dixon, B.R., Barkema, H.W., Hurnik, D., and Estey, C., (2012): Occurrence of Giardia and Cryptosporidium in pigs on Prince Edward Island, Canada. Vet Parasitol. 28 (1): 1-9.

6. Nematian J, Gholamrezanezhad A, Nematian E. (2008). Giardiasis and other intestinal parasitic infections in relation to anthropometric indicators of malnutrition: a large, population based survey of schoolchildren in Tehran. Ann Trop Med Parasitol, 2008; 102(3): 209-214.

7. Ryan, U. and Caccio, S. M. (2013): Zoonotic potential of Giardia. Int.J. $\quad$ Parasitol. 43 (12-13): 943-956.

8. Julio, C.,Vilares, A.,Oleastro, M., Ferreira, I., Gomes, S.,Monteiro, L.,Nunes, B.,Tenreiro, R., and Angelo, H. (2012): Prevalence and risk factors for 
Giardia duodenalis infection among children: A case study in Portugal. Parasites \& Vectors, 27 (5):22-29.

9. Mohran, (2013): Genotyping of Giardia lamblia in human and animal feces in Qaliopiagovernate. Thesis, Benha University.

10.De Lucio, A., Martínez-Ruiz, R., Merino, F.J., Bailo, B., Aguilera, M., Fuentes, I., and Carmena, D. (2015): Molecular genotyping of Giardia duodenalis isolates from symptomatic individuals attending two major public hospitals in Madrid, Spain. PLoS One 10 (12): e0143981.

11.Duldova, A. Juris, P. Jurisova, S. Jarcuska, P. and Kremery, v. (2016): Epidemiology and geographical distribution of gastrointestinal parasitic infection in humans in Slovakia. Helminthologia. 53 (4): 309 - 317.
12.Bernard N. and Samuel B. N. (2011): Giardia lamblia: a major parasitic cause of childhood diarrhoea in patients attending a district hospital in Ghana. Parasit Vectors. 4 (1): 163-170.

13.Heehong, S., Davaasuren, A., Young, J., Davaajav, A., Shin-Hyeong, C., Won-Ja, L. and Sang-Eun, L. (2014): Molecular characterization of Giardiaduodenalis and Cryptosporidium parvum in fecal samplesof individuals in Monogolia. Am. J. Trop. Med. Hyg. 90 (1): 43-47.

14.El-Badry, A.A., Mohammed,A.F., Abdul Gawad, E. (2017): Predominance of Giardia intestinalis assemblage $\mathrm{B}$ in diarrhoeic children in Sharkia, Egypt. Parasitologists United Journal. ISSN: 1687-7942, Vol. 10, No. 1 \& 2. 